Pacific Journal of Mathematics

A RATE OF GROWTH CRITERION FOR UNIVERSALITY OF 


\title{
A RATE OF GROWTH CRITERION FOR UNIVERSALITY OF REGRESSIVE ISOLS
}

\author{
JUDITH GERSTING
}

Let $\alpha$ be an infinite retraceable set having the property that if $a_{n}$ is the retraceable function ranging over $\alpha$, then for each partial recursive function $p(x)$, there is a number $m$ such that $p\left(a_{n}\right)<a_{n+1}$ whenever $n \geqq m$ and $p\left(a_{n}\right)$ is defined. Recently, T. G. McLaughlin proved the existence of retraceable sets having this property and also of such sets having recursively enumerable complements. In addition, he showed that sets of this kind will be immune and that each of their regressive subsets will be retraceable. The main result of this paper states that (infinite) regressive isols that contain a retraceable set with this property will be universal. As corollary to this result we obtain the existence of cosimple universal regressive isols.

We will assume that the reader is familiar with the terminology and main results of the papers listed in the references. We let $E$ denote the collection of all nonnegative integers, $A$ the collection of all isols, and $\Lambda_{R}$ the collection of all regressive isols. If $f: E \rightarrow E$ is a recursive and combinatorial function, then we let $C_{f}$ denote its canonical extension to $\Lambda$. If $\alpha \subseteq E$, then we say that $\alpha$ is cofinite if the complement of $\alpha$ is a finite set, i.e., if there is a number $m$ such that $n \geqq m \Rightarrow n \in \alpha$. If $f$ is a partial function (from a subset of $E$ into $E$ ) then we denote the domain and range of $f$ by $\delta f$ and $\rho f$, respectively. If $f$ is a partial function and $x$ and $y$ any numbers, then we write " $f(x)<y$ " to mean either that $f(x)$ is undefined or else $f(x)$ is defined and $f(x)<y$; we interpret " $f(x) \leqq y$ " in a similar manner. We recall from [7] that an infinite isol $A$ is universal if for each pair of recursive combinatorial functions $f$ and $g$, one has

$$
C_{f}(A)=C_{g}(A) \Longrightarrow\{n \mid f(n)=g(n)\} \text { is cofinite . }
$$

2. T-regressive isols. We call a retraceable function $a_{n}$ T-retraceable if it has the property that for each partial recursive function $p(x)$, there is a number $m$ such that

$$
n \geqq m \Longrightarrow p\left(a_{n}\right)<a_{n+1} \text {. }
$$

We call an infinite retraceable set T-retraceable if it is the range of a T-retraceable function. A useful result of T. G. McLaughlin, [8], is

(1) cosimple $T$-retraceable sets exist. McLaughlin also observed that 
(2) T-retraceable sets are immune.

We call an infinite regressive isol T-regressive if it contains a $T$-retraceable set. By (1) and (2) it follows that both $T$-regressive isols and cosimple $T$-regressive isols exist. We let $\Lambda_{T R}$ denote the collection of all $T$-regressive isols. Let $\alpha$ be a $T$-retraceable set and $\delta$ any finite set. Then it can be easily shown that the set $\alpha \cup \delta$ is also T-retraceable. It follows from this property that

$$
T \in \Lambda_{T R} \text { and } n \in E \Longrightarrow T+n \in \Lambda_{T R} \text {. }
$$

REMARK. We wish to give next an example of a $T$-retraceable set. In a proof not yet published, T. G. McLaughlin used movable markers to obtain the existence of a cosimple $T$-retraceable set. Our proof here will be a little easier because we do not require that the $T$-retraceable set that we construct be cosimple.

Let $\left\{p_{i}(x)\right\}$ be an enumeration of all partial recursive functions of one variable such that each partial recursive function appears exactly once in the enumeration. Let the function $u_{n}$ be defined by

$$
u_{n}=\sum_{0 \leqq i, x \leqq n} p_{i}(x) \text {, }
$$

where we set $p_{i}(x)=0$ if $p_{i}(x)$ is undefined. By [3, Lemma 2], there is a retraceable function $t_{n}^{*}$ such that

$$
t_{n}^{*}>u_{n}, \quad \text { for each } n \in E \text {. }
$$

Let $t_{n}=2 t_{n}^{*}$. Then $t_{n}$ is also a retraceable function, and ranges over a set of even numbers. In addition, for each partial recursive function $p_{e}(x)$ (e denoting the index in the enumeration), we see that

$$
n \geqq e \Longrightarrow p_{e}(n) \leqq u_{n}<t_{n} .
$$

Let the function $a_{n}$ be defined by

$$
\left\{\begin{array}{l}
a_{0}=t_{1}=t(1), \\
a_{n}=t^{n+1}(2 n+1), \quad \text { for } n \geqq 1 .
\end{array}\right.
$$

Because the retraceable function $t_{n}$ assumes only even values, it is readily seen that $a_{n}$ is a retraceable function. Also, for each partial recursive function $p_{e}(x)$,

$$
n \geqq e \Longrightarrow t^{n+1}(2 n+1) \geqq e,
$$

and therefore by (4) we have, for $n \geqq e$

$$
\begin{aligned}
p_{e}\left(a_{n}\right) & =p_{e}\left(t^{n+1}(2 n+1)\right) \\
& <t^{n+2}(2 n+1) \\
& <t^{n+2}(2 n+3)=a_{n+1} .
\end{aligned}
$$


Hence $a_{n}$ is a $T$-retraceable function, and its range will be a $T$-retraceable set.

3. The main result. The main result that we wish to prove is that T-regressive isols are universal. For this purpose we will need two lemmas, each of which involves a relation $T \leqq * u_{n}$ between infinite regressive isols $T$ and functions $u_{n}$; the relation was introduced in [3] and we now recall how it is defined. If $T$ is an infinite regressive isol and $u_{n}$ any function from $E$ into $E$, then $T \leqq * u_{n}$ if there is a regressive function $t_{n}$ that ranges over a set in $T$ such that $t_{n} \leqq{ }^{*} u_{n}$; here $t_{n} \leqq * u_{n}$ means that the mapping $t_{n} \rightarrow u_{n}$ has a partial recursive extension. It can be shown that if $T \leqq * u_{n}$, then $t_{n} \leqq * u_{n}$ for every regressive function $t_{n}$ that ranges over a set in $T$ [3]. Also if $T$ is any infinite regressive isol and $u_{n}$ any recursive function, then $T \leqq * u_{n}$. The first lemma we will state without proof because it can be readily obtained from results in [3].

LEMMA 1. Let $T$ be an infinite regressive isol and let $u_{n}$ be any function such that $T \leqq * u_{n}$. Let $u_{n} \geqq 1$, for each number $n \in E$. Then $\sum_{T} u_{n} \in \Lambda_{R}$ and if $t_{n}$ is any regressive function that ranges over a set in $T$, then

$$
j\left(t_{0}, 0\right), \cdots, j\left(t_{0}, u_{0}-1\right), j\left(t_{1}, 0\right), \cdots, j\left(t_{1}, u_{1}-1\right), \cdots,
$$

represents a regressive enumeration of a set belonging to $\sum_{T} u_{n}$.

Lemma 2. Let $T$ be a T-regressive isol and let $u_{n}$ and $\widetilde{u}_{n}$ be any functions such that both $T \leqq * u_{n}$ and $T \leqq * \widetilde{u}_{n}$. Let $u_{n} \geqq 1$ and $\widetilde{u}_{n} \geqq 1$, for each number $n \in E$. Let

$$
\sum_{T} u_{n}=\sum_{T} \widetilde{u}_{n} .
$$

Then the set $\left\{n \mid u_{n}=\widetilde{u}_{n}\right\}$ is cofinite.

Proof. Let $t_{n}$ be a $T$-retraceable function that ranges over a set in $T$, and let $\tau=\rho t_{n}$. By Lemma 1 ,

$$
\begin{aligned}
& j\left(t_{0}, 0\right), \cdots, j\left(t_{0}, u_{0}-1\right), j\left(t_{1}, 0\right), \cdots, j\left(t_{1}, u_{1}-1\right), \cdots, \\
& j\left(t_{0}, 0\right), \cdots, j\left(t_{0}, \widetilde{u}_{0}-1\right), j\left(t_{1}, 0\right), \cdots, j\left(t_{1}, \widetilde{u}_{1}-1\right), \cdots,
\end{aligned}
$$

represent regressive enumerations of sets belonging to $\sum_{T} u_{n}$ and $\sum_{T} \widetilde{u}_{n}$ respectively. Let the regressive functions determined by these two enumerations be given by $g_{n}$ and $\widetilde{g}_{n}$ respectively. In light of (5) we see that $g_{n}$ and $\widetilde{g}_{n}$ will be regressive functions that range over sets in the same isol, and therefore by results in [5] it follows that $g_{n} \simeq \widetilde{g}_{n}$, i.e., there is a one-to-one partial recursive function $p(x)$ such that 


$$
\rho g \subset \delta p \text { and }(\forall n)\left[p\left(g_{n}\right)=\widetilde{g}_{n}\right] \text {. }
$$

In addition, because $T \leqq * u_{n}$ and $T \leqq * \widetilde{u}_{n}$ there will also be partial recursive functions $f_{1}$ and $f_{2}$ such that

$$
\begin{aligned}
& \tau \subset \delta f_{1} \text { and }(\forall n)\left[f_{1}\left(t_{n}\right)=u_{n}\right], \\
& \tau \subset \delta f_{2} \text { and }(\forall n)\left[f_{2}\left(t_{n}\right)=\widetilde{u}_{n}\right] .
\end{aligned}
$$

Define the four functions,

$$
\begin{aligned}
& p_{1}(x)=k p j(x, 0), \\
& p_{2}(x)=k p j\left(x, f_{1}(x)-1\right), \\
& q_{1}(x)=k p^{-1} j(x, 0), \\
& q_{2}(x)=k p^{-1} j\left(x, f_{2}(x)-1\right),
\end{aligned}
$$

where $k$ denotes the familiar recursive function having the property that $k j(x, y)=x$. Then each of these functions is partial recursive and will map $\tau$ into $\tau$ in the following way:

$$
\begin{array}{ll}
\text { if } p j\left(t_{n}, 0\right)=j\left(t_{k}, y\right) & \text { then } p_{1}\left(t_{n}\right)=t_{k}, \\
\text { if } p j\left(t_{n}, u_{n}-1\right)=j\left(t_{k}, y\right) & \text { then } p_{2}\left(t_{n}\right)=t_{k}, \\
\text { if } p^{-1} j\left(t_{n}, 0\right)=j\left(t_{k}, y\right) & \text { then } q_{1}\left(t_{n}\right)=t_{k}, \text { and } \\
\text { if } p^{-1} j\left(t_{n}, \tilde{u}_{n}-1\right)=j\left(t_{k}, y\right) & \text { then } q_{2}\left(t_{n}\right)=t_{k} .
\end{array}
$$

For each number $n \in E$, let

$$
\begin{array}{ll}
p_{1}\left(t_{n}\right)=t_{n^{\prime}}, & p_{2}\left(t_{n}\right)=t_{n^{\prime \prime}}, \\
q_{1}\left(t_{n}\right)=t_{n^{*}}, & q_{2}\left(t_{n}\right)=t_{n^{* *}} .
\end{array}
$$

Because $t_{n}$ is a $T$-retraceable function and $p_{1}(x)$ is a partial recursive function, there will exist a number $m_{1}$ such that

$$
n \geqq m_{1} \Longrightarrow p_{1}\left(t_{n}\right)<t_{n+1} \text {. }
$$

Combining this with the property that $t_{n}$ is a retraceable function and hence strictly increasing, we see that

$$
\begin{aligned}
n \geqq m_{1} & \Longrightarrow p_{1}\left(t_{n}\right)<t_{n+1} \\
& \Longrightarrow t_{n^{\prime}}<t_{n+1} \\
& \Longrightarrow n^{\prime} \leqq n .
\end{aligned}
$$

Therefore,

$$
n \geqq m_{1} \Longrightarrow n^{\prime} \leqq n .
$$

In a similar fashion it can be shown that there are numbers $m_{2}, k_{1}$ and $k_{2}$ such that 
(B)

(D)

$$
\begin{aligned}
& n \geqq m_{2} \Longrightarrow n^{\prime \prime} \leqq n, \\
& n \geqq k_{1} \Longrightarrow n^{*} \leqq n, \\
& n \geqq k_{2} \Longrightarrow n^{* *} \leqq n
\end{aligned}
$$

Let

$$
\bar{m}=\max \left\{m_{1}, m_{2}, k_{1}, k_{2}\right\},
$$

and let $m$ be a number chosen such that

$$
\left\{\begin{array}{l}
m \geqq \bar{m} \text { and } \\
(\forall n)\left[n \geqq m \Longrightarrow n^{\prime} \geqq \bar{m} \text { and } n^{*} \geqq[\bar{m}] .\right.
\end{array}\right.
$$

To complete the proof, we now verify that

$$
n \geqq m=u_{n}=\widetilde{u}_{n} \text {. }
$$

In view of the definition of the functions $g_{n}$ and $\widetilde{g}_{n}$ and the relation (6), we see that to verify (8), it suffices to prove

$$
n \geqq m \Longrightarrow p j\left(t_{n}, 0\right)=j\left(t_{n}, 0\right) ;
$$

and this will be our approach here. To prove the relation $(*)$, assume that $n \geqq m$ and let

$$
p j\left(t_{n}, 0\right)=j\left(t_{r}, x\right) .
$$

Then we wish to verify

(a) $r=n$ and

(b) $\quad x=0$.

For (a). We first note that $r=n^{\prime}$ and therefore by (7) and (A), we have

$$
r \leqq n
$$

If $x=0$, then $r^{*}=n$. In this event we have by (7) and $n \geqq m$ that $n^{\prime}=r \geqq k_{1}$ so by (C) it follows that $r^{*} \leqq r$, and hence also that $n \leqq r$. Combining this with (10), we see that if $x=0$ then $r=n$, and we are done.

Assume now that $x>0$; then $0<x \leqq \widetilde{u}_{r}-1$. Consider the diagram,

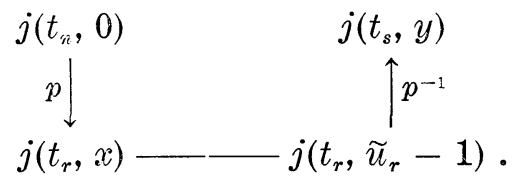

We note first that $n \leqq s$ and $s=r^{* *}$. Also from (7) and $n \geqq m$ we have $n^{\prime}=r \geqq k_{2}$. By (D) it follows then that $s=r^{* *} \leqq r$. Hence 
$n \leqq r$; and combining this relation with (10) implies $r=n$. This completes the proof of part (a).

For (b). By part (a), we know that

$$
p j\left(t_{n}, 0\right)=j\left(t_{n}, x\right),
$$

where $0 \leqq x \leqq \widetilde{u}_{n}-1$. We wish to show here that $x=0$. It can be proven by an argument similar to that in part (a), that one will also have

$$
p^{-1} j\left(t_{n}, 0\right)=j\left(t_{n}, y\right),
$$

for some $y, 0 \leqq y \leqq u_{n}-1$; and we will omit the details. We will therefore have the following diagram,

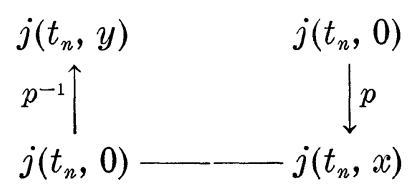

and this array will only be possible if $x=y=0$. This verifies part (b) and completes the proof.

COROLlaRY 1. Let $T$ be a T-regressive isol and let $u_{n}$ and $\widetilde{u}_{n}$ be any functions such that both $T \leqq * u_{n}$ and $T \leqq * \widetilde{u}_{n}$. Then

$$
\sum_{T^{\prime}} u_{n}=\sum_{T^{\prime}} \widetilde{u}_{n} \Longrightarrow\left\{n \mid u_{n}=\widetilde{u}_{n}\right\} \text { is cofinite. }
$$

Proof. Let the symbol 1 denote the recursive function identically equal to 1 . Then $T \leqq * 1$, and by [3, Lemma 3] both $T \leqq *\left(u_{n}+1\right)$ and $T \leqq *\left(\widetilde{u}_{n}+1\right)$. Consider the following implications:

$$
\begin{aligned}
\sum_{T} u_{n}=\sum_{T} \tilde{u}_{n} & \Longrightarrow \sum_{T} u_{n}+\sum_{T} 1=\sum_{T} \tilde{u}_{n}+\sum_{T} 1 \\
& \Longrightarrow \sum_{T}\left(u_{n}+1\right)=\sum_{T}\left(\widetilde{u}_{n}+1\right) \\
& \Longrightarrow\left\{n \mid u_{n}+1=\widetilde{u}_{n}+1\right\} \text { is cofinite } \\
& \Longrightarrow\left\{n \mid u_{n}=\tilde{u}_{n}\right\} \text { is cofinite } .
\end{aligned}
$$

The first implication is clear, the second follows from results in [3], the third from Lemma 2 and the last one is clear. Together they imply the desired result and this completes the proof.

Theorem 1. Let $T$ be a T-regressive isol. Then $T$ is universal.

Proof. Let $f$ and $g$ be any recursive combinatorial functions. We wish to show that 


$$
C_{f}(T)=C_{g}(T) \Longrightarrow\{x \mid f(x)=g(x)\} \text { is cofinite } .
$$

Let the functions $e_{n}$ and $\widetilde{e}_{n}$ be defined by

$$
\begin{aligned}
& \left\{\begin{array}{l}
e_{0}=f(0), \\
e_{n}=f(n)-f(n-1), \quad \text { for } n \geqq 1,
\end{array}\right. \\
& \left\{\begin{array}{l}
\widetilde{e}_{0}=g(0), \\
\widetilde{e}_{n}=g(n)-g(n-1), \quad \text { for } n \geqq 1 .
\end{array}\right.
\end{aligned}
$$

Clearly $e_{n}$ and $\tilde{e}_{n}$ are recursive functions, since combinatorial functions are also increasing. In addition to this, $e_{n}$ and $\widetilde{e}_{n}$ will be the $e$-difference functions associated with the functions $f$ and $g$ respectively, [see 1]. Hence by [1, Corollary 2] we see that

$$
\begin{aligned}
& C_{f}(T)=\sum_{T^{\prime}+1} e_{n}, \quad \text { and } \\
& C_{g}(T)=\sum_{T^{\prime}+1} \widetilde{e}_{n} .
\end{aligned}
$$

To verify (13) assume that $C_{f}(T)=C_{g}(T)$. Then

$$
\sum_{T+1} e_{n}=\sum_{T+1} \widetilde{e}_{n} \text {. }
$$

Because $T$ is a $T$-regressive isol, it follows from (3) that $T+1$ will also be a $T$-regressive isol. Also both $T+1 \leqq * e_{n}$ and $T+1 \leqq * \widetilde{e}_{n}$, since $e_{n}$ and $\widetilde{e}_{n}$ are each recursive functions. In light of Corollary 1 , it follows from (16) that there is a number $m \in E$, such that

$$
n \geqq m \Longrightarrow e_{n}=\widetilde{e}_{n} \text {. }
$$

If $m=0$, then it is easy to see from (14) and (15) that $f(n)=g(n)$ for each number $n \in E$; and the desired result follows. Let us assume now that $m \geqq 1$. Let

$$
\begin{aligned}
U & =\sum_{(T+1-m)} e_{m+n} \\
& =\sum_{(T+1-m)} \widetilde{e}_{m+n} .
\end{aligned}
$$

Then, from (16) we have

$$
e_{0}+\cdots+e_{m-1}+U=\widetilde{e}_{0}+\cdots+\widetilde{e}_{m-1}+U ;
$$

and hence also

$$
e_{0}+\cdots+e_{m-1}=\widetilde{e}_{0}+\cdots+\widetilde{e}_{m-1} \text {. }
$$

In view of (14) and (15), it follows from (18) that $f(m-1)=g(m-1)$. Finally, combining this fact with (14), (15) and (17) we see that

$$
n \geqq m-1 \Longrightarrow f(n)=g(n) \text {. }
$$


Therefore the set $\{n \mid f(n)=g(n)\}$ is cofinite, and this completes the proof of the theorem.

THEOREM 2. There exist cosimple universal regressive isols.

Proof. Use Theorem 1 and the fact that cosimple $T$-regressive isols exist.

4. Concluding remarks. (A) The existence of universal regressive isols was first proved by E. Ellentuck in some notes not yet published. Also, in some unpublished notes, J. Barback showed that multiple-free regressive isols exist and that these are also universal.

(B) We have also proved the following result, stated here without proof, of which Theorem 1 is a corollary:

Let $T$ be a $T$-regressive isol, and let $f$ and $g$ be any recursive combinatorial functions. Then

$$
C_{f}(T) \leqq C_{g}(T) \Longrightarrow\{x \mid f(x) \leqq g(x)\} \text { is cofinite } .
$$

(C) We wish to state without proofs some additional properties of the collection $A_{T R}$ of all $T$-regressive isols. We will assume that the reader is familiar with the three relations $\leqq, \leqq$ and $*$ defined between infinite regressive isols; the first two are defined in [6], and the third in [2].

Theorem A. Let $A \in \Lambda_{R}-E$ and $T \in \Lambda_{T R}$. Then

(a) $T$ is multiple-free,

(b) $A \leqq T \Longrightarrow A \in \Lambda_{T R}$,

(c) $A \leqq T \Longrightarrow A \in \Lambda_{T R}$.

Theorem B. Let $A, B, T \in \Lambda_{T R}$. Then

(a) $A * B \Longrightarrow \min (A, B) \in \Lambda_{T R}$,

(b) $A+B \in \Lambda_{R} \Longrightarrow \min (A, B) \in \Lambda_{T R}$,

(c) $A, B \leqq T \Longrightarrow \min (A, B) \in \Lambda_{T R}$.

The author wishes to thank Professor Joseph Barback for his help during a seminar which he conducted at Arizona State University.

\section{REFERENCES}

1. J. Barback, Recursive functions and regressive isols, Math. Scand. 15 (1964), 29-42.

2. - Two notes on regressive isols, Pacific J. Math. 16 (1966), 407-420.

3. — Regressive upper bounds, Seminario Matematico, 39 (1967), 248-272.

4. J. C. E. Dekker, Infinite series of isols, Proc. of the Symp. on Recursive Function Theory, Amer. Math. Soc., Providence, R. I., (1962), 77-96.

5. - The minimum of two regressive isols, Math. Zeit. 83 (1964), 345-366. 
6. J. C. E. Dekker and J. Myhill, Recursive equivalence types, Univ. California Publ. Math. (N.S.) 3 (1960), 67-213.

7. E. Ellentuck, Universal isols, Math. Zeit. 98 (1967), 1-8.

8. T. G. McLaughlin, Hereditarily retraceable isols, Bull. Amer. Math. Soc. 73 (1967), $113-115$.

9. J. Myhill, Recursive equivalence types and combinatorial functions, Bull. Amer. Math. Soc. 64 (1958), 373-376.

10. A. Nerode, Extensions to isols, Ann. of Math. 73 (1961), 362-403.

11. F. J. Sansone, Combinatorial functions and regressive isols, Pacific J. Math. 13 (1963), 703-707.

Received June 19, 1968. Research on this paper was supported in part by an Arizona State University Summer Fellowship for Graduate Teaching Assistants.

ARIZONa State University

TEMPE, ARIZONA 



\title{
PACIFIC JOURNAL OF MATHEMATICS
}

\author{
EDITORS
}

\author{
H. ROYDEN \\ Stanford University \\ Stanford, California \\ RICHARD PIERCE \\ University of Washington \\ Seattle, Washington 98105
}

\author{
J. DUGUNDJI \\ Department of Mathematics \\ University of Southern California \\ Los Angeles, California 90007 \\ BASIL GORDON \\ University of California \\ Los Angeles, California 90024
}

\section{ASSOCIATE EDITORS}

E. F. BECKENBACH
B. H. NeumanN

F. WOLF
K. YoshidA

\section{SUPPORTING INSTITUTIONS}

\author{
UNIVERSITY OF BRITISH COLUMBIA \\ CALIFORNIA INSTITUTE OF TECHNOLOGY \\ UNIVERSITY OF CALIFORNIA \\ MONTANA STATE UNIVERSITY \\ UNIVERSITY OF NEVADA \\ NEW MEXICO STATE UNIVERSITY \\ OREGON STATE UNIVERSITY \\ UNIVERSITY OF OREGON \\ OSAKA UNIVERSITY \\ UNIVERSITY OF SOUTHERN CALIFORNIA
}

\author{
STANFORD UNIVERSITY \\ UNIVERSITY OF TOKYO \\ UNIVERSITY OF UTAH \\ WASHINGTON STATE UNIVERSITY \\ UNIVERSITY OF WASHINGTON

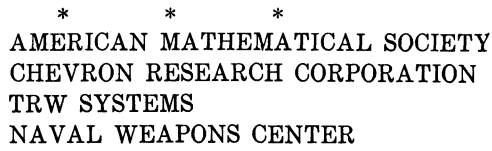

The Supporting Institutions listed above contribute to the cost of publication of this Journal, but they are not owners or publishers and have no responsibility for its content or policies.

Mathematical papers intended for publication in the Pacific Journal of Mathematics should be in typed form or offset-reproduced, double spaced with large margins. Underline Greek letters in red, German in green, and script in blue. The first paragraph or two must be capable of being used separately as a synopsis of the entire paper. It should not contain references to the bibliography. Manuscripts, in duplicate if possible, may be sent to any one of the four editors. Please classify according to the scheme of Math. Rev. 36, 1539-1546. All other communications to the editors should be addressed to the managing editor, Richard Arens, University of California, Los Angeles, California, 90024.

50 reprints are provided free for each article; additional copies may be obtained at cost in multiples of 50 .

The Pacific Journal of Mathematics is published monthly. Effective with Volume 16 the price per volume (3 numbers) is $\$ 8.00$; single issues, $\$ 3.00$. Special price for current issues to individual faculty members of supporting institutions and to individual members of the American Mathematical Society: $\$ 4.00$ per volume; single issues $\$ 1.50$. Back numbers are available.

Subscriptions, orders for back numbers, and changes of address should be sent to Pacific Journal of Mathematics, 103 Highland Boulevard, Berkeley, California, 94708.

PUBLISHED BY PACIFIC JOURNAL OF MATHEMATICS, A NON-PROFIT CORPORATION

Printed at Kokusai Bunken Insatsusha (International Academic Printing Co., Ltd.), 7-17, Fujimi 2-chome, Chiyoda-ku, Tokyo, Japan. 


\section{Pacific Journal of Mathematics}

\section{Vol. 31, No. $3 \quad$ BadMonth, 1969}

George E. Andrews, On a calculus of partition functions .................. 555

Silvio Aurora, A representation theorem for certain connected rings ............ 563

Lawrence Wasson Baggett, A note on groups with finite dual spaces ............. 569

Steven Barry Bank, On majorants for solutions of algebraic differential equations in regions of the complex plane ............................... 573

Klaus R. Bichteler, Locally compact topologies on a group and the corresponding continuous irreducible representations ......................... 583

Mario Borelli, Affine complements of divisors ....................... 595

Carlos Jorge Do Rego Borges, A study of absolute extensor spaces ............. 609

Bruce Langworthy Chalmers, Subspace kernels and minimum problems in Hilbert

spaces with kernel function ...................................... 619

John Dauns, Representation of L-groups and F-rings................. 629

Spencer Ernest Dickson and Kent Ralph Fuller, Algebras for which every

indecomposable right module is invariant in its injective envelope ...........

Robert Fraser and Sam Bernard Nadler, Jr., Sequences of contractive maps and fixed

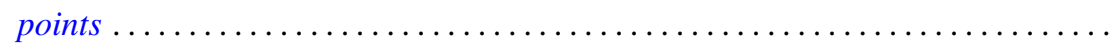

Judith Lee Gersting, A rate of growth criterion for universality of regressive

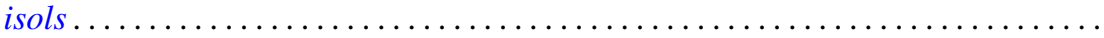

Robert Fred Gordon, Rings in which minimal left ideals are projective ............

Fred Gross, Entire functions of several variables with algebraic derivatives at certain algebraic points

W. Charles (Wilbur) Holland Jr. and Stephen H. McCleary, Wreath products of ordered permutation groups .........................

W. J. Kim, The Schwarzian derivative and multivalence .................. 717

Robert Hamor La Grange, Jr., On $(\mathrm{m}-\mathrm{n})$ products of Boolean algebras ......... 725

Charles D. Masiello, The average of a gauge ........................ 733

Stephen H. McCleary, The closed prime subgroups of certain ordered permutation

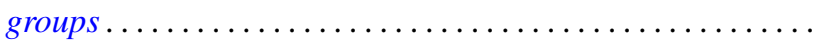

Richard Roy Miller, Gleason parts and Choquet boundary points in convolution measure algebras ...............................

Harold L. Peterson, Jr., On dyadic subspaces ........................ 773

Derek J. S. Robinson, Groups which are minimal with respect to normality being intransitive........................................... 777

Ralph Edwin Showalter, Partial differential equations of Sobolev-Galpern type . . . 787

David Slepian, The content of some extreme simplexes ................... 795

Joseph L. Taylor, Noncommutative convolution measure algebras ............. 809

B. S. Yadav, Contractions of functions and their Fourier series ............... 827

Lindsay Nathan Childs and Frank Rimi DeMeyer, Correction to automorphisms of separable algebras" ....................... 833

Moses Glasner and Richard Emanuel Katz, Correction to: "Function-theoretic degeneracy criteria for Riemannian manifolds".............

Satish Shirali, Correction to: "On the Jordan structure of complex Banach

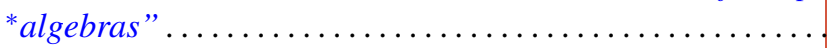

